\section{Peregrinação familiar: a busca por cuidado em saúde mental infantil}

\author{
Family odysseys: the search for infant mental \\ health care
}

\section{Peregrinación familiar: la búsqueda de cuidado en salud mental infantil}

Patricia Santos de Souza Delfini 1

Isabella Teixeira Bastos 1

Alberto Olavo Advincula Reis 1

doi: 10.1590/0102-311X00145816

\section{Resumo}

O objetivo foi analisar o itinerário percorrido por famílias de crianças atendidas em um Centro de Atenção Psicossocial Infantojuvenil na busca por tratamento em saúde mental. Foram realizadas Observações Participantes do serviço estudado e Grupos Focais com familiares de crianças atendidas. A pesquisa qualitativa usou como aporte teórico-metodológico a Análise Institucional e o material foi discutido tendo em vista o modo de atenção psicossocial. A busca dos familiares quando se confrontam com o sofrimento psíquico de uma criança é um indicador privilegiado para aquilatar potencialidades e fragilidades na construção da rede de atenção, bem como para revelar o entendimento dos familiares a respeito dos problemas de saúde mental e seus tratamentos. Verificou-se a presença de forças contraditórias nas ações cotidianas de atenção, demonstrando ora a força transformadora do instituinte, ora a cristalização e manutenção do instituído. Nesse sentido, o modelo hegemonicamente instituído - focado na doença, fragmentando o sujeito e a atenção a ele dirigida - tem sido tensionado por uma força instituinte que propõe reposicionar o sujeito, bem como incorporar o sofrimento psíquico como integrante da saúde geral, articulando serviços e ações em um modelo de rede. A despeito do novelo de embaraços com os quais os familiares se deparam em sua peregrinação por cuidados, existem avanços que caminham na direção da atenção psicossocial e apontam para desafios a serem enfrentados. Tais avanços têm ancoragem nas tecnologias relacionais - acolhimento, vínculo, confiança e responsabilização entre os diversos atores envolvidos no cuidado.

\section{Correspondência}

P. S. S. Delfini

Departamento de Saúde, Ciclos de Vida e Sociedade,

Faculdade de Saúde Pública, Universidade de São Paulo. Av. Dr. Arnaldo 715, sala 203, São Paulo, SP 01246-904, Brasil. patriciadelfini@gmail.com

1 Faculdade de Saúde Pública, Universidade de São Paulo, São Paulo, Brasil. 


\section{Introdução}

No Brasil, até o início do século XXI, a população infantojuvenil não havia sido praticamente contemplada com políticas públicas de saúde mental consistentes. Atualmente, os cuidados voltados às crianças em sofrimento psíquico são orientados por um modelo público de rede de atenção composta por um conjunto de serviços de saúde e de outros setores.

Tal modelo é composto de um cenário paradoxal marcado, de um lado, por um tipo de política higienista-menorista e, de outro, voltado à criança como sujeito de direitos, dado pelo aparato político-jurídico do Estatuto da Criança e do Adolescente, da Convenção Internacional dos Direitos das Crianças e do Plano Nacional de Promoção, Proteção e Defesa do Direito de Crianças e Adolescentes à Convivência Familiar e Comunitária 1. Assinalam-se, ainda, programas de cuidado primário à saúde da mulher, infância e puericultura higienistas e fragmentários do início do século XX, que tiveram o mérito de reverter quadros de mortalidade infantil e morbimortalidade evitáveis 2,3.

Essa configuração híbrida deve-se, provavelmente, à assimilação da ambiguidade dada por uma posição de vanguarda no ordenamento político da problemática infantojuvenil e pelas consequências de indicadores sociais dignos dos países mais pobres do planeta para essa população 4 . Apesar das contradições postas, tal composição redundou, inegavelmente, em uma mudança que colocou a criança na condição de sujeito e direitos.

$\mathrm{Na}$ constituição de uma rede pública de atenção em saúde mental infantojuvenil 5,6, pautada pela clínica ampliada 7, ressaltam-se as indicações pelo acolhimento universal, encaminhamento implicado e corresponsável, construção permanente da rede e da intersetorialidade no território, corresponsabilização por demandas complexas que envolvem a saúde mental infantil e construção compartilhada das necessidades de saúde 8,9 .

No que concerne à composição estrutural dessa rede, a Portaria no 3.088/2011 instituiu a Rede de Atenção Psicossocial (RAPS) para pessoas com sofrimento ou transtorno mental e com necessidades decorrentes do uso de crack, álcool e outras drogas, no âmbito do Sistema Único de Saúde (SUS) 9 . No caso da infância, destacam-se como pontos de atenção 10: a Estratégia Saúde da Família (ESF), a unidade básica de saúde (UBS), as equipes de Consultório na rua, o Núcleo de Apoio à Saúde da Família (NASF), o Centro de Convivência e Cultura (CECCO), o Centro de Atenção Psicossocial Infantojuvenil (CAPSi), os serviços de urgência e emergência e os hospitalares.

Os CAPSi, regulamentados pela Portaria no 336/2002 11, são serviços estratégicos e focados na atenção em saúde mental de crianças e adolescentes em sofrimento psíquico intenso, sob a lógica de atenção psicossocial. Esses equipamentos atuam como componentes de uma rede horizontal - em oposição a um modelo piramidal de atenção à saúde - cujo centro é o sujeito em sofrimento. Esses serviços têm sido implantados de modo irregular e desigual no país, em quantidade insuficiente frente à demanda.

Costa-Rosa et al. 12,13 propõem a designação de modo psicossocial a um novo paradigma para a compreensão e construção de práticas próprias da Reforma Psiquiátrica, em oposição ao modo asilar e em substituição às teorias ou modelos psicológicos estimados insuficientes para lidar com os desafios de uma abordagem pública e coletiva da saúde mental.

O modo psicossocial se contrapõe, particularmente, ao modo asilar em quatro pontos principais: na definição de seu objeto e meios de intervenção, nas formas de organização dos serviços, nos modos de relacionamento com os usuários e população, e nas implicações éticas de sua prática 12,13. No paradigma psicossocial, entende-se que (1) o objeto de intervenção é o sujeito, com suas peculiaridades, inclusive o sofrimento que o acomete e o contexto do qual faz parte; (2) as intervenções terapêuticas são constituídas por um conjunto de ações variadas de acordo com as necessidades e possiblidades de cada sujeito; (3) os objetivos do cuidado incluem diminuição do sofrimento, ampliação das possibilidades de vida e inclusão social; (4) as relações entre os serviços são caracterizadas pela proximidade visando a um cuidado compartilhado, com corresponsabilização entre os envolvidos e em rede; (5) os profissionais envolvidos no cuidado são de diversos setores e profissões; (6) os instrumentos e a postura dos profissionais envolvem escuta, acolhimento e vínculo; e (7) a participação do sujeito em sofrimento é ativa em seu cuidado.

Tal perspectiva tem nas tecnologias relacionais, ou tecnologias-leves, segundo Merhy 14, sua principal ancoragem. Nesse sentido, as noções de acolhimento - como uma postura afetiva pela vida e 
sofrimento das pessoas - escuta qualificada, vínculo, confiança, corresponsabilização e humanização da assistência são fundamentais nas práticas de saúde 15 e têm especial importância na saúde mental, pois são os operadores primordiais do cuidado.

A clínica ampliada 16 propõe um alargamento na compreensão do processo saúde/doença, do objeto de intervenção e das ações de cuidado, em relação a uma perspectiva clínica restritiva, que tende a fragmentar o paciente e intervir de maneira isolada em cada problema.

No caso da infância, a clínica é necessariamente ampliada, pois o cuidado em saúde de crianças só é efetuado se desenvolvido de modo interdisciplinar e intersetorial 7, bem como na mobilização de seu ambiente social e institucional (família e escola) mais próximo. Contudo, o modelo médico-biológico, não raro, vai ao encontro do imediatismo da sociedade moderna e da lógica da produtividade que rege os processos de trabalho 17, gerando resistência para a aceitação da proposta da atenção psicossocial.

Adicionalmente, ainda persistem problemas, como crianças desassistidas ou à procura de tratamento, carência de serviços e profissionais de saúde diante das necessidades da população, desenvolvimento de ações de cuidado pouco articuladas entre os serviços e setores 17,18,19.

No campo da pesquisa, os trabalhos voltados ao tema da atenção psicossocial são em menor número quando comparados aos estudos de epidemiologia, neurociência e psiquiatria 20 e, na especificidade da infância, esta ausência é ainda maior ${ }^{5}$. Dentre as pesquisas existentes, pouco se menciona a construção da atenção em saúde mental infantil e das redes de cuidado com base nos usuários dos serviços, ou seja, das crianças e famílias em atendimento e, mais especificamente ainda, valendo-se das condições concretas de suas vivências em busca de respostas aos problemas com os quais se deparam. Alguns estudos que têm como foco os familiares de crianças em sofrimento psíquico destacam a falta de intervenções terapêuticas dirigidas a elas nos serviços, a dificuldade das equipes para lidar com as diversas configurações familiares, a sobrecarga emocional vivenciada especialmente pela mãe, principal cuidadora destas crianças, e as dificuldades encontradas na procura por tratamento 21,22,23,24,25.

Essa busca dos familiares por atendimento pode ser um indicador privilegiado para aquilatar potencialidades e fragilidades na construção da rede de atenção. Ainda, o itinerário percorrido pelas famílias pode ser revelador do entendimento concreto dos familiares a respeito das dimensões próprias e diferenciais que existem entre os modelos de base médico-asilar e os de base psicossocial.

Tendo em vista tais questões, o presente estudo intenta analisar o itinerário percorrido por famílias de crianças atendidas no CAPSi na busca por tratamento em saúde mental, visando a contribuir para a potencialização das políticas públicas neste setor e à efetivação das ações de cuidado adequadas às suas necessidades.

\section{Métodos}

Recorte de pesquisa de doutorado, cujo referencial teórico-metodológico se apoiou na Análise Institucional Francesa 26,27. As técnicas adotadas para o seu desenvolvimento foram Observação Participante e Grupo Focal, no qual usou-se como estratégia a construção de itinerários terapêuticos.

A pesquisa de campo ocorreu em um município de médio porte - cerca de 450 mil habitantes da Grande São Paulo, Brasil, entre setembro de 2014 e abril de 2015, envolveu familiares de crianças atendidas em um CAPSi - único da categoria existente na cidade. O serviço, inaugurado em 2005, passou por ampla reformulação estrutural e de projeto de atendimento em 2013, ano em que a saúde mental foi priorizada pela gestão municipal, com expansão de serviços e profissionais, especialmente na atenção básica, visando à implantação de uma Rede de Atenção Psicossocial territorializada, apoiada na perspectiva da atenção psicossocial.

A observação participante visou a captar a realidade e compreender a vida cotidiana no próprio ambiente estudado 28. As observações foram registradas em um diário de pesquisa - instrumento técnico da Análise Institucional para captar as implicações do pesquisador, a vivência rotineira do campo, a temporalidade e o desenrolar da pesquisa 29.

O Grupo Focal consistiu de sessões de discussão de grupo - uma hora e meia por encontro - em que os participantes expressaram percepções, crenças, valores, atitudes e representações sobre o tema proposto 30,31,32. O grupo foi composto por nove familiares de crianças atendidas no CAPSi (Tabela 1), participantes de grupo de orientação, indicados pela equipe do serviço, além de um moderador e 
Tabela 1

Caracterização dos familiares participantes do grupo focal.

\begin{tabular}{|c|c|c|c|c|c|}
\hline \multicolumn{3}{|c|}{ Identificação do participante } & \multicolumn{3}{|c|}{ Identificação da criança } \\
\hline Sujeito & Relação com a criança & Idade & Sexo & Idade & Tempo no CAPSi \\
\hline 1 & mãe & 31 & masculino & 8 & 1 ano \\
\hline 2 & mãe & 44 & masculino & 6 & 3 anos \\
\hline 3 & mãe & 39 & masculino & 8 & 2 anos \\
\hline 4 & mãe & 32 & feminino & 7 & 3 anos \\
\hline 5 & avó & 62 & masculino & 8 & 1 ano \\
\hline 6 & pai & 35 & masculino & 9 & 2 meses \\
\hline 7 & pai & 41 & masculino & 8 & 5 anos \\
\hline 8 & pai & 30 & masculino & 7 & 3 anos \\
\hline 9 & padrasto & 37 & masculino & 7 & 2 anos \\
\hline
\end{tabular}

um observador 30,31,32. Participaram do grupo diversos familiares que se responsabilizam pelo cuidado da criança: quatro mães, uma avó, três pais e um padrasto. Vale ressaltar que a ampla participação masculina nesse contexto diverge dos dados encontrados em outras pesquisas, que apontam a predominância, em proporções muito superiores, de mulheres como as principais cuidadoras das crianças com problemas de saúde mental 21,23,25,33.

Utilizamos, como estratégia metodológica, a construção de itinerários terapêuticos, isto é, trajetórias seguidas na busca de solução para problemas ${ }^{34}$, que contribui para a compreensão do comportamento em relação ao cuidado e da utilização dos serviços de saúde 34,35 . Sendo assim, no primeiro encontro, entregamos material gráfico aos participantes, solicitando que desenhassem individualmente os caminhos percorridos com as crianças e os lugares em que estiveram desde que perceberam algo diferente. Após essa construção, cada participante compartilhou e descreveu o seu desenho. Foram necessários três encontros para que todos apresentassem seus itinerários.

O segundo e terceiro encontros foram iniciados com a leitura de uma narrativa construída por nós pesquisadores, com base na transcrição da sessão anterior 36,37. Essa leitura, com caráter de restituição na perspectiva da Análise Institucional 29, levou os participantes a validar, complementar, corrigir e/ ou aprofundar as discussões realizadas. Desse modo, iniciamos o processo interpretativo, entendendo que ele é construído com a participação daqueles que se pretende compreender.

As sessões, áudio-gravadas e transcritas em sua integralidade, juntamente com as anotações do observador do grupo e com o diário de pesquisa compuseram o material empírico da investigação que foi reunido e lido repetidas vezes, visando à ordenação e interpretação dos dados 32 . Os resultados foram, então, organizados em temas centrais que expressam as estruturas de maior relevância e as ideias principais presentes na pesquisa, tendo em vista o referencial teórico da Análise Institucional e os pressupostos do modo de atenção psicossocial 12 .

O estudo obedeceu aos critérios e diretrizes da ética em pesquisa com seres humanos, conforme Resolução no 466/2012 do Conselho Nacional de Saúde, e obteve parecer consubstanciado pelo Comitê de Ética em Pesquisa das instituições proponente e participante.

\section{Análise e discussão dos resultados}

Os resultados foram organizados em quatro temas: o reconhecimento dos problemas, a procura inicial por tratamento, os caminhos percorridos e a chegada ao CAPSi.

A Figura 1 apresenta o itinerário construído por um dos familiares e reúne elementos semelhantes a outros depoimentos que, juntamente com trechos de falas de outros participantes, serão apresentados para ilustrar a análise e discussão. 


\section{Figura 1}

Itinerário construído por um familiar participante.

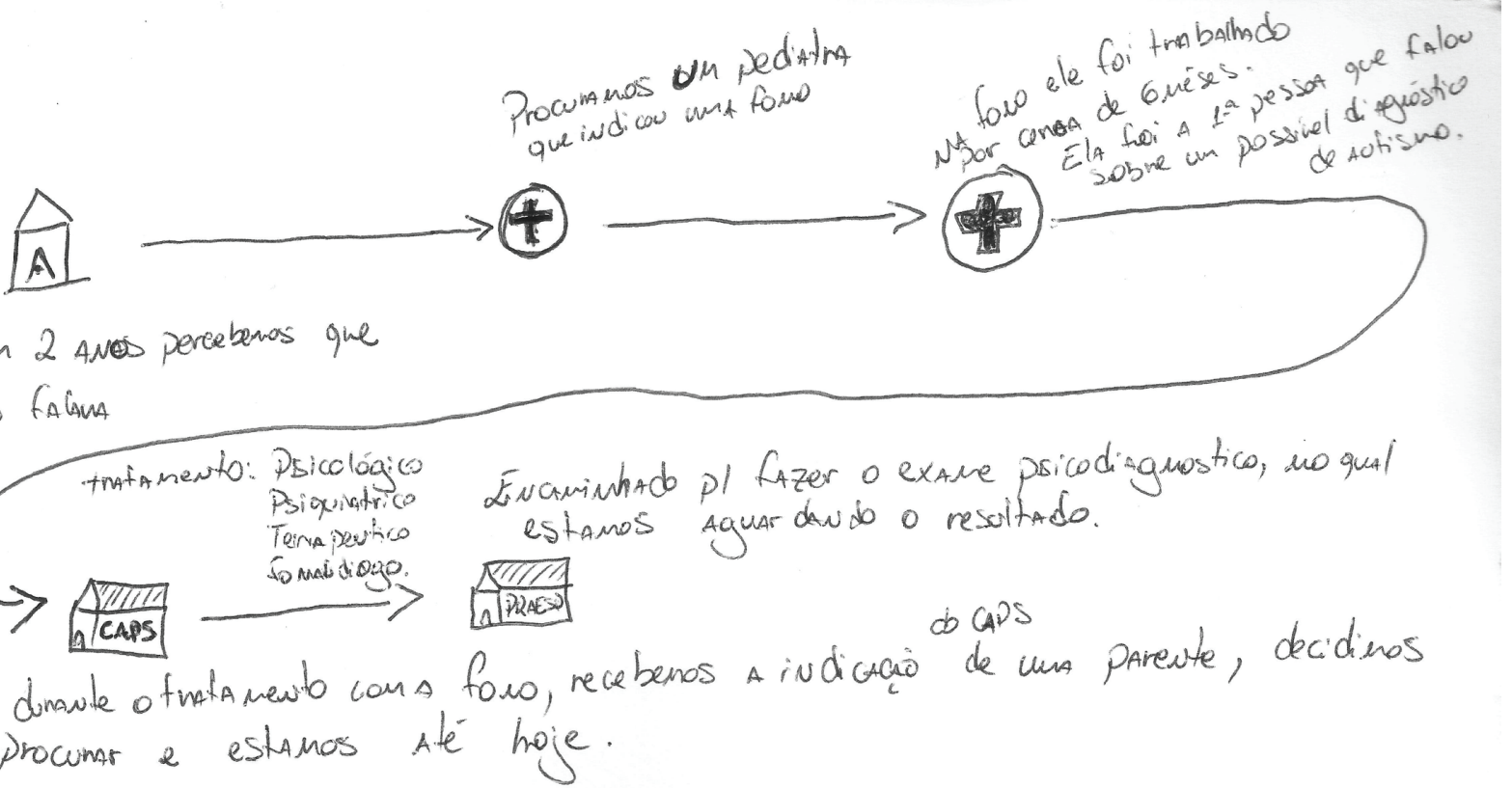

CAPS: Centro de Atenção Psicossocial.

Fonte: elaboração própria.

\section{O reconhecimento dos problemas pelos familiares - "eu olhava para ela e ia me angustiando... o que será que ela tem?"}

Os próprios familiares, na maioria dos casos, relataram terem sido os primeiros a perceber algo de diferente na criança, como no exemplo da Figura 1. Contudo, descrevem que as primeiras opiniões recebidas - de amigos, parentes e até mesmo de profissionais - seguiram a linha de que "cada criança tem seu tempo". Esses, insatisfeitos com essas respostas, cada um em seu momento, procuraram novas opiniões.

"[Minha filha] tinha aquela dificuldade de pedir, de falar alguma coisa, ela chorava muito, não dormia à noite, e eu passava a noite em claro com ela (...) eu não sabia. Então, ia me angustiando, porque eu falava: nossa, o que ela tem? (...) Aí, eu fui procurar ajuda no posto".

O principal problema percebido que chamava a atenção dos familiares foi ausência ou dificuldade na fala - mencionado por sete dos nove participantes. A fala, por constituir importante elemento da vida humana na condução da sociabilidade 38 , é facilmente identificável e alvo de preocupação inicial.

“...com idade pra falar, ele não desenvolveu a fala e tinha muita dificuldade em dormir e a gente começou a questionar com os vizinhos, com os colegas e aquela conversa de que cada criança tem seu tempo".

Outros problemas citados foram dificuldade no sono, referido por cinco pessoas, e a agitação extrema, também descrita por cinco participantes. Mais do que a dificuldade em si, os participantes da pesquisa relataram que foi a intensidade e a combinação de mais de um dos problemas que os mobilizaram a procurar ajuda.

Em quase todos os casos, o ingresso da criança na escola representou uma importante mudança, uma vez que, neste ambiente, os profissionais da educação reiteravam o reconhecimento dos problemas inicialmente percebidos pelos pais e reforçavam a necessidade de tratamento. Assim, a dificuldade no contexto escolar, quer fosse relacionada à aprendizagem ou à interação social, foi descrita pelos participantes. 
"Foi quando ele foi pra escolinha e com a ajuda da professora nós entendemos que ele realmente não estava se desenvolvendo como deveria uma criança normal".

Os problemas relatados nesta pesquisa se assemelharam às principais queixas iniciais encontradas em outras investigações realizadas em CAPSi 38,39,40, nas quais houve relevância o comprometimento na linguagem e fala, as dificuldades escolares, agitação e agressividade. Assim, a partir dessas primeiras problemáticas vividas, as famílias começaram suas buscas.

\section{A procura inicial por tratamento e os primeiros encaminhamentos - "ele não tem nada, isso é um problema normal"}

Um ponto em comum às diferentes trajetórias, tal como se observa no exemplo da Figura 1, está na procura pelo médico pediatra, na maioria dos casos da UBS, diante das dificuldades iniciais. Inicialmente, esse profissional tendia a minimizar os problemas relatados, entendendo-os como normais, ou a realizar encaminhamentos para exames ou para especialistas, dados similares aos encontrados em outra pesquisa 23

"Aos dois anos, ele não falava e sempre quando passávamos pelo pediatra, ele falava que isso era um problema normal e que um dia ele ia falar (...). Depois, foi passado pra fazer exame de audição (...), não constatou nenhum problema e ai foi levando".

Os encaminhamentos variaram entre especialidades: fonoaudiólogo, neuropediatra, neurologista, psiquiatra, otorrinolaringologista, psicólogo e fisioterapeuta. Apesar dessa diversidade, provavelmente relacionada à especificidade de cada situação e às hipóteses iniciais feitas pelo pediatra, os familiares relataram um sentimento de solidão e abandono nos direcionamentos e procuras que seguiram. Tal sentimento parece estar relacionado à organização fragmentada dos serviços e à predominância da lógica do encaminhamento, apoiadas na noção, ainda hegemônica, de que problemas de saúde mental não fazem parte das ações dos médicos da Atenção Básica, que não se consideram aptos ou responsáveis por estas situações 41 .

Os profissionais especialistas foram procurados de diversos modos pelos familiares - serviços públicos ou privados, do próprio município ou de cidades vizinhas, por indicação de profissionais, colegas, parentes ou vizinhos. Nesse percurso se agregam e se avolumam filas de espera e dificuldades de se encontrar profissionais e serviços específicos, o que desencadeou desgastes e frustrações para as famílias.

"Ele [pediatra do posto] pegou e me encaminhou [para neuro, fono e otorrino], demorou um pouco pra sair, aí quando saiu, saiu a neurologista em Diadema, e a fono pro Mario Covas. Aí foi aquela separação de caminhos".

Além disso, algumas respostas obtidas dos profissionais, tais como: "vocês o mimam demais", "cada criança tem seu tempo", acentuaram o sentimento de pouca escuta ou desvalorização de suas preocupações. O resultado negativo de um exame acompanhado da resposta "ele não tem nada", situação vivenciada por diversos familiares, em vez de trazer alívio, trazia mais angústia, sendo encarada como mais uma porta fechada e a necessidade de procurar, sem pistas, novos caminhos. A fala a seguir evidencia esse distanciamento, assim como demonstra um tipo de atenção em saúde baseado em uma prática disciplinar e restritiva, divergente do cuidado alicerçado no modo psicossocial:

"A gente procurou um médico, em um certo ponto ele foi até ignorante, ele era um neuropediatra. Ele chegou a falar pra gente assim: 'pais, vocês têm que ensinar seu filho a falar', ele pegou a caneta e falou assim: 'isso daqui é caneta, fala pra ele: ó ca-ne-ta, que ele tem é preguiça de falar'. E a gente via que não era isso".

O encaminhamento para o CAPSi, serviço em que a pesquisa foi desenvolvida, ocorreu mediante indicação de profissionais de saúde ou da escola - o que é corroborado por outros estudos 41,42 - em diferentes momentos para os participantes: para alguns no início das buscas, para outros, depois de muita caminhada. A procura espontânea também apareceu na pesquisa, tendo sido, em geral, precedida de indicação informal de profissionais, parentes e conhecidos.

Assim, percebemos um movimento dos familiares em busca de mais (quantidade) e novos (qualidade) recursos para atender às suas dificuldades. Essa procura esteve relacionada a concepções e ações que tendiam ora para a integralidade da atenção, ora para um trabalho fragmentado, como discutiremos a seguir. 
Os caminhos percorridos pelas famílias - "cada um fala uma coisa, você vai juntar tudo e não dá resultado nenhum"

A procura por tratamento foi relatada como longa, desgastante e frustrante. A nomeação que alguns familiares dão aos seus percursos, e que usaremos como analisador da instituição saúde mental, é a de "peregrinação", que é definida como uma jornada longa e exaustiva, conforme o Dicionário Houaiss.

Os analisadores, tal como postulados pela análise institucional, são fenômenos reveladores e catalisadores 26,27 que surgem em uma intervenção que evidenciam, fazem aparecer a instituição invisível, mostrando suas contradições, limites e possibilidades. Contribuem para que se conheça a instituição - a dinâmica contraditória e dialética entre forças instituídas e instituintes que resultam na institucionalização, ou seja, no produto destas forças contraditórias. Entendemos que a peregrinação seja um analisador, pois ela permite identificar aspectos ocultos e contraditórios presentes na instituição, que se tensionam em diversos pontos 10, dos quais destacaremos dois: a concepção sobre problemas de saúde mental e a forma de organização dos serviços.

Vale ressaltar que a peregrinação assume uma função simbólica, de busca de lugar sagrado ao qual se dirige para realizar uma salvação ou cura. Foucault 43 traz à baila a dimensão da peregrinação no âmbito da saúde mental ao analisar o papel da Nau dos Insensatos que na Idade Média passava pelo Reno recolhendo loucos e outros marginalizados. Para ele, esse barco era um lugar de uma simbólica peregrinação em busca de alguma forma de "razão". A procura incessante das famílias por novos recursos e serviços parece incluir essa dimensão, revelando um anseio por uma solução precisa para o problema, baseada em uma lógica simplista do tipo queixa/conduta.

“O que falta aqui são pessoas pra falar 'o seu filho realmente tem isso' (...). E os pais que tão começando agora com seu filho de dois, três anos, vai acontecer a mesma coisa. Vai demorar quatro, cinco, seis, sete anos (...) pra achar um especialista certo pra saber que é aquilo que seu filho tem".

A expectativa acerca do diagnóstico psiquiátrico da criança, tema bastante discutido no grupo realizado, a busca por profissionais especialistas e o pedido por medicação são indicativos da predominância da perspectiva biomédica 41 e do paradigma psiquiátrico medicalizador 10, modelos ainda hegemônicos. Entretanto, estiveram presentes discursos e ações que indicam concepções que se aproximam do paradigma psicossocial 12,13, como, por exemplo, falas críticas sobre a rápida realização do diagnóstico:

"Então, às vezes eles colocam o diagnóstico muito rápido. Eles colocam assim, seu filho tem isso, seu filho tem isso. É isso aí, a própria criança passa a pensar que ele mesmo tem, porque os parentes vão comentar, os amigos vão comentar e, às vezes, não é nem isso que ele tem".

Vale ressaltar que entendemos que o diagnóstico, além de sua função de compreensão sobre o sofrimento da criança e de direcionamento do tratamento, tem um papel de referenciamento, balizamento e ordenamento cognitivo e existencial para as famílias. Contudo, quando realizado de modo precipitado ou como resposta única e capaz de apontar, por si, a intervenção e a compreensão do caso, pode levar à estigmatização da criança, reduzindo-a a um rótulo psiquiátrico.

Assim, possivelmente, não seria propriamente um diagnóstico que o familiar esperava dos profissionais consultados, mas uma resposta plena, autêntica e compreensível, assim como um acolhimento e tratamento para a difícil situação vivida. Percebemos que, alguns profissionais consultados estabelecem com as famílias um contato distanciando, uma relação descomprometida, uma comunicação vazia e inautêntica ${ }^{44}$, apresentados na forma de respostas imprecisas e encaminhamentos desimplicados, levando-as a novas procuras.

Ainda, a falta de articulação entre os profissionais procurados, assim como as divergências teórico-práticas presentes no campo da saúde mental, se apresentaram nos direcionamentos discrepantes que as famílias receberam:

“...cada um fala uma coisa. Você passa com o psiquiatra, ele fala que seu filho tem uma coisa, você passa pelo psicólogo, já discorda. Você passa pelo neuro, ele fala outra coisa, você passa pelo fono, já é outra coisa que ele tá falando. Então você vai juntar isso daí, não deu em nada, não dá resultado nenhum".

Essas respostas divergentes acentuam o sentimento das famílias de ficarem "à própria sorte", sem acolhida para sua vivência, especialmente quando não têm acesso aos debates sobre diferentes modos de compreensão e ação nesse campo. Tais dificuldades foram apresentadas também em pesquisa realizada com mães de crianças autistas 23 , o que reitera a importância do acolhimento e escuta às angustias vivenciadas pelas famílias. 
No que se refere à organização dos serviços e modos de relação entre eles, tem-se, de um lado, a lógica do encaminhamento e da desresponsabilização pelos casos e, do outro, a do compartilhamento em um modelo de rede de atenção. Ambos se apresentam de modo sobreposto no estudo, embora haja uma predominância da primeira, o que é corroborado por outras pesquisas 17,45.

Nessa lógica, ancorada no paradigma asilar, vemos que cada profissional faz sua avaliação de modo isolado e encaminha - via guias de papel - a família a outro profissional, caso entenda a necessidade de intervenções especializadas, sendo que dificilmente a família retorna ao profissional de origem. Os profissionais-especialistas, em geral, fazem novas avaliações ou exames à procura de uma resposta à problemática apresentada pela criança, mantendo um circuito que não se fecha.

"Você corre pra cá, corre pra lá e você vai indo onde você quer achar o recurso, só que você nunca acha o recurso”.

Presenciamos, nas observações realizadas, ações pontuais de discussão de caso e de compartilhamento de intervenções entre profissionais de diferentes serviços. Além disso, nas reuniões de equipe, percebemos um empenho dos profissionais para um trabalho em rede, com intercâmbio entre serviços e corresponsabilização pelos casos, apoiado na perspectiva da atenção psicossocial. Contudo, essas ações pareciam isoladas, provavelmente devido às dificuldades encontradas no cotidiano dos serviços: excesso de demanda, falta de recursos, diferentes concepções dos profissionais.

A identificação que os participantes demostraram com os itinerários uns dos outros evidencia o quanto o ciclo foi repetitivo e poderia ser construído de uma maneira menos sofrida e solitária, com base em uma rede de serviços que pudesse de fato oferecer uma sustentação e continência às famílias.

"Eu não sabia o que era autismo, comecei a aprender no grupo de pais, eu via pais relatando, falei 'nossa, é a minha história' (...). Aquela angústia, desespero, porque você procura uma porta, procura outra, um fala isso, outro fala aquilo".

A falta de escuta efetiva, de confiança e de holding 46 - sustentação e acolhimento para as angústias - vivida pelos familiares em seus percursos fomentam a incessante peregrinação na procura por cuidado.

\section{A chegada ao CAPSi, o acolhimento e os desafios da rede: "no CAPS nós sentimos um conforto"}

A chegada ao CAPSi, tal como relatado por alguns participantes, minimizou a angústia e atenuou a procura solitária por novos serviços ao oferecer um ambiente facilitador e um acolhimento, no qual dúvidas, angústias e medos foram sustentados, mediante uma disponibilidade para escutar.

"Nós começamos a passar no CAPS e, aí nós sentimos, vamos dizer assim, um conforto (...) porque foi o único que abraçou. No fonoaudiólogo que nós passamos pelo convênio não tinha essa interação com o caso dele. Era simplesmente ir lá, passava aquela 'sessãozinha' de meia hora e ele ia embora e cada um com seu problema (...). Aqui as pessoas parecem que são mais ligadas".

Nesse sentido, vimos que a oferta de um espaço acolhedor, com investimento na relação, no comprometimento com o outro, no acompanhamento longitudinal, tal como propõe o paradigma psicossocial, teve um efeito positivo, mostrando-se como importante elemento do cuidado para os familiares.

"Eles [profissionais de outros serviços] nunca pegavam a causa e abraçavam, eles sempre iam distanciando, ou seja, eles faziam o atendimento, pediam pra fazer um exame e 'não tem nada, pai, não tem nenhum problema'. Mandava a gente pra casa, procurava outro neuro, procurava um outro psiquiatra, um outro psicólogo e sempre a mesma coisa, ninguém nunca abraçava a causa”.

Alguns participantes afirmam que se sentem ouvidos pela equipe sempre que precisam e que o grupo de orientação que frequentam tem fundamental importância. Há um empenho do serviço em inserir os familiares em grupos, embora não tenhamos dados precisos sobre esta inserção. Diversas pesquisas indicam a escassez de ações voltadas aos familiares em serviços como esse 21,22,23,24,25,38.

Por outro lado, as famílias se queixaram da falta de profissionais e intervenções específicas, além do frágil trabalho em rede. Sobre esse último, vale destacar o duplo mandato do CAPSi, terapêutico e gestor, como ferramenta potente para a superação das peregrinações solitárias dos familiares, uma vez que caberia aos profissionais desse serviço atuarem como ordenadores da demanda em saúde mental do território e mobilizadores do trabalho em rede. O papel gestor parece ainda não ter sido completamente incorporado pelo serviço estudado, embora algumas ações concretamente operadas 
tenham sido observadas, assim como discussões sobre o tema em espaços de reuniões do serviço e da rede territorial. Cabe, ainda, dizer que embora o CAPSi estudado funcione desde 2005, seu modelo de atuação, até 2013 - ano em que houve mudança de gestão e de perspectiva de atenção em saúde mental - era isolado dos demais serviços e centrado em si. As mudanças propostas para a RAPS do município se mostram ainda em processo de construção, com avanços e resistências. Tal como afirma Amarante 47 , a transformação do modelo instituído não se esgota com a implantação de serviços e contratação de profissionais, dependendo de um conjunto de transformações em diversas dimensões.

Portanto, podemos aventar a possibilidade de que os casos que chegam atualmente aos serviços são apreendidos por uma lógica de encaminhamento modificada, quando comparados aos casos em que predomina a peregrinação solitária das famílias, ou tensionada pelo efeito de sua disputa com a lógica do cuidado territorializada em implantação no local estudado.

\section{Considerações finais}

Os conflitos e contradições estiveram presentes na pesquisa, o que indica um processo vivo, com o envolvimento de pessoas que se posicionam de maneiras distintas, desde as mais transformadoras até as mais resistentes. Contradições não são, necessariamente, impedimentos, mas podem se oferecer como constitutivos de processos e movimentos em que mais de um modelo se apresenta portando lógicas diversas que se tensionam.

A construção dos itinerários terapêuticos e seu compartilhamento entre os familiares em um grupo focal trouxeram para um nível explícito, exibindo toda a sua dramaticidade, os caminhos palmilhados pelas famílias, as barreiras e similaridades encontrados. Percebemos, igualmente, que nas experiências relatadas as vivências singulares e diferenciais puderam ser intercambiadas e ressignificadas pelos participantes.

O modelo hegemonicamente instituído, relacionado ao modo asilar, do tipo queixa-conduta, que fragmenta o sujeito e a atenção, tem sido tensionado por uma força instituinte que propõe reposicionar o usuário e incorporar o sofrimento psíquico como integrante da saúde. Essa tensão está presente nas ações cotidianas de maneira conflituosa, ora na força transformadora do instituinte, ora na cristalização e manutenção do instituído. Dessa forma, podem se entrever nos relatos obtidos que, a despeito do novelo de embaraços com os quais os familiares se deparam em sua peregrinação por cuidados adequados, existem também avanços que caminham na direção da atenção psicossocial e apontam para importantes desafios a serem enfrentados. Tais avanços estão relacionados ao cuidado construído em uma perspectiva que envolve acolhimento, construção de vínculos de afeto e confiança e disponibilidade de escuta efetiva às mais variadas situações. Por outro lado, as diversas dificuldades de se efetivar o cuidado territorializado e em rede - escassez de recursos e serviços, organização do trabalho distinta, entendimentos discrepantes - representam obstáculos para a implantação de um cuidado alicerçado no modo de atenção psicossocial.

A contradição que pauta a motivação dos familiares no seu longo e penoso caminho de busca indicaria não só uma mudança de cultura no âmbito da representação da denominada loucura e dos meios de enfrentá-la, como refletiria a intensa luta e tensionamentos em obra no interior das práticas, atitudes e visões presentes no campo da saúde mental. Talvez esses conflitos possam indicar não uma crise paralisante do modelo, mas uma possibilidade de um modelo alternativo às propostas hoje existentes, capazes de contemplar as demandas profundas da população. 


\section{Colaboradores}

P. S. S. Delfini participou da concepção, delineamento da pesquisa, coleta, análise e interpretação dos dados e redação do artigo. I. T. Bastos participou da coleta, análise e interpretação dos dados e redação do artigo. A. O. A. Reis orientou a pesquisa e participou da concepção, delineamento da pesquisa, análise e interpretação dos dados e redação do artigo.

\section{Agradecimentos}

Agradecemos o apoio financeiro da Coordenação de Aperfeiçoamento de Pessoal do Nível Superior (Capes) para a realização desta pesquisa.

\section{Referências}

1. Lauridsen-Ribeiro E, Tanaka OY. Organização de serviços no Sistema Único de Saúde para o cuidado de crianças e adolescentes com problemas de saúde mental. In: Lauridsen-Ribeiro E, Tanaka OY, organizadores. Atenção em saúde mental para crianças e adolescentes no SUS. São Paulo: Editora Hucitec; 2010. p. 147-69.

2. Araújo JP, Silva RMM, Collet N, Neves ET, Toso BRGO, Viera CS. História da saúde da criança: conquistas, políticas e perspectivas. Rev Bras Enferm 2014; 67:1000-7.

3. Campos CEA. A organização dos serviços de atenção primária à saúde no Brasil. Rev Bras Med Fam Comunidade 2006; 2:131-47.
4. Rizzini I, Pilotti F. A arte de governar crianças. Lições do passado, reflexões para o presente. In: Rizzini, I, Pilotti F, organizadores. A arte de governar crianças. A história das políticas sociais, da legislação e da assistência à infância no Brasil. 3a Ed. São Paulo: Cortez Editora; 2011. p. 323-9.

5. Couto MCV. Política de saúde mental para crianças e adolescentes: especificidades e desafios da experiência brasileira (2001-2010) [Tese de Doutorado]. Rio de Janeiro: Universidade Federal do Rio de Janeiro; 2012. 
6. Departamento de Ações Programáticas Estratégica; Departamento de Atenção Básica, Secretaria de Atenção à Saúde, Ministério da Saúde. Cadernos de atenção básica 34: saúde mental. Brasília: Ministério da Saúde; 2013.

7. Vicentin M. Infância e adolescência: uma clínica necessariamente ampliada. Rev Ter Ocup 2006; 17:10-7.

8. Departamento de Ações Programáticas Estratégicas, Secretaria de Atenção à Saúde, Ministério da Saúde. Caminhos para uma política de saúde mental infanto-juvenil. Brasília: Ministério da Saúde; 2005. (Série B. Textos Básicos em Saúde).

9. Ministério da Saúde. Portaria no 3.088, de 23 de dezembro de 2011. Institui a Rede de Atenção Psicossocial para pessoas com sofrimentos ou transtorno mental e com necessidades decorrentes do uso de crack, álcool e outras drogas no âmbito de Sistema Único de Saúde (SUS). Diário Oficial da União 2011; 26 dez.

10. Ministério da Saúde. Atenção psicossocial a crianças e adolescentes no SUS: tecendo redes para garantir direitos. Brasília: Ministério da Saúde; 2014.

11. Ministério da Saúde. Portaria no 336, de 19 de fevereiro de 2002. Diário Oficial da União 2002; 20 fev.

12. Costa-Rosa A, Luzio CA, Yasui S. Atenção Psicossocial: rumo a um novo paradigma na saúde mental coletiva. In: Amarante P, organizador. Archivos de saúde mental e atenção psicossocial. Rio de Janeiro: Nau Editora; 2003. p. 13-44.

13. Costa-Rosa A. A instituição de saúde mental como dispositivo social de produção de subjetividade. Estud Psicol (Campinas) 2012; 29:115-26.

14. Merhy EE. Saúde: a cartografia do trabalho vivo. São Paulo: Editora Hucitec; 2002.

15. Núcleo Técnico da Política Nacional de Humanização, Secretaria de Atenção à Saúde, Ministério da Saúde. Acolhimento nas práticas de produção de saúde. Brasília: Ministério da Saúde; 2006. (Série B. Textos Básicos de Saúde).
16. Secretaria de Atenção à Saúde, Ministério da Saúde. Política Nacional de Humanização da Atenção e Gestão do SUS. Clínica ampliada e compartilhada. Brasília: Ministério da Saúde; 2009. (Série B Textos Básicos de Saúde).

17. Delfini PSS, Reis AOA. Articulação entre serviços públicos de saúde nos cuidados voltados à saúde mental infantojuvenil. Cad Saúde Pública 2012; 28:357-66.

18. Couto MCV, Duarte CS, Delgado PGG. A saúde mental infantil na Saúde Pública brasileira: situação atual e desafios. Rev Bras Psiquiatr (1967) 2008; 30:390-8.

19. Delfini PSS. Centro de Atenção Psicossocial Infantojuvenil e Estratégia de Saúde da Família: articulação das ações voltadas à saúde mental de crianças e adolescentes [Dissertação de Mestrado]. São Paulo: Faculdade de Saúde Pública, Universidade de São Paulo; 2010.

20. Delgado PGG. O desafio da produção de conhecimento sobre a reforma psiquiátrica brasileira. Ciênc Saúde Coletiva 2015; 20:312.

21. Bustamante V, Santos I. Arranjos familiares e possibilidades terapêuticas em um serviço de saúde mental infantil. Pensando Fam 2015; 19:115-31.

22. Monteiro ARM, Teixeira LA, Silva RSM, Rabelo KPS, Tavares SFV, Távora RCO. Sofrimento psíquico em crianças e adolescentes: a busca pelo tratamento. Esc Anna Nery Rev Enferm 2012; 16:523-9.

23. Favero-Nunes MA, Santos MA. Itinerário terapêutico percorrido por mães de crianças com transtorno autístico. Psicol Reflex Crít 2010; 23:208-21.

24. Dombi-Barbosa C, Bertolino-Neto MM, Fonseca FL, Tavares CM, Reis AOA. Condutas terapêuticas de atenção às famílias da população. Rev Bras Crescimento Desenvolv Hum 2009; 19:262-8.

25. Muylaert CJ, Delfini PSS, Reis AOA. Relações de gênero entre familiares cuidadores de crianças e adolescentes de serviços de saúde mental. Physis (Rio J.) 2015; 25:41-58. 
26. Lourau R. A análise institucional (1975). 2a Ed. Petrópolis: Editora Vozes; 1995.

27. L’Abbate S. Análise institucional e intervenção: breve referência à gênese social e histórica de uma articulação e sua aplicação na saúde coletiva. Mnemosine 2012; 8:194-219.

28. Valladares L. Os dez mandamentos da observação participante. Rev Bras Ciênc Soc 2007; 22:153-5.

29. Lourau R. René Lourau na UERJ. Análise institucional e práticas de pesquisa. Rio de Janeiro: EdUERJ; 1993.

30. Barbour R. Grupos focais. Porto Alegre: Editora Artmed; 2009.

31. Westphal MF, Bógus CM, Faria MM. Grupos focais: experiências precursoras em programas educativos em saúde no Brasil. Bol Oficina Sanit Panam 1996; 120:472-82.

32. Minayo MCS. O desafio do conhecimento: pesquisa qualitativa em saúde. 14a Ed. São Paulo: Editora Hucitec; 2014.

33. Delfini PSS, Dombi-Barbosa C, Fonseca FS, Reis AOA. Perfil dos usuários de um centro de atenção psicossocial infantojuvenil da Grande São Paulo, Brasil. Rev Bras Crescimento Desenvolv Hum 2009; 19:226-36.

34. Cabral ALLV, Martinez-Hemáez A, Andrade EIG, Cherchiglia ML. Itinerários terapêuticos: o estado da arte da produção científica no Brasil. Ciênc Saúde Coletiva 2011; 16:4433-42.

35. Costa ALRC, Figueiredo DLB, Medeiros LHL, Mattos M, Maruyama SAT. O percurso na construção dos itinerários terapêuticos de famílias e redes para o cuidado. In: Pinheiro R, Martins PH, organizadores. Avaliação em saúde na perspectiva do usuário: abordagem multicêntrica. Rio de Janeiro: Instituto de Medicina Social, Universidade do Estado do Rio de Janeiro; 2011. p. 195-202.

36. Furtado JP, Onocko-Campos R. A participação de diferentes grupos de interesse na geração de conhecimentos sobre a rede de serviços avaliada. In: Onocko-Campos R, Furtado JP, Passos E, Nebevides R, organizadores. Pesquisa avaliativa em saúde mental: desenho participativo e efeitos de narratividade. São Paulo: Editora Hucitec; 2008. p. 231-48.
37. Miranda L, Figueiredo MD, Ferrer AL, Onocko-Campos R. Dos grupos focais aos grupos focais narrativos: uma descoberta no caminho da pesquisa. In: Onocko-Campos R, Furtado JP, Passos E, Nebevides R, organizadores. Pesquisa avaliativa em saúde mental: desenho participativo e efeitos de narratividade. São Paulo: Editora Hucitec; 2008. p. 249-77.

38. Reis AOA. Os Centros de Atenção Psicossocial Infantojuvenis no Estado de São Paulo [Tese de Livre Docência]. São Paulo: Faculdade de Saúde Pública, Universidade de São Paulo; 2010.

39. Ronchi JP, Avellar LZ. Saúde mental da criança e do adolescente: a experiência do Capsi da cidade de Vitória-ES. Psicol Teor Prát 2010; 12:71-84.

40. Arrué AM, Neves ET, Terra MG, Magago TSBS, Jantsch LB, Pieszak GM, et al. Crianças/ adolescentes com necessidades especiais em Centro de Atenção Psicossocial. Rev Enferm UFSM 2013; 3:227-37.

41. Gomes FMA, Cintra AMO, Ricas J, Vecchia MD. Saúde mental infantil na atenção primária à saúde: discursos de profissionais médicos. Saúde Soc 2015; 24:244-58.

42. Reis AOA, Fonseca FL, Rolim-Neto ML, Delfini PSS, organizadores. As crianças e os adolescentes dos Centros de Atenção Psicossocial Infantojuvenil. São Paulo: Schoba; 2012.

43. Foucault M. História da loucura na idade clássica. 9a Ed. São Paulo: Editora Perspectiva; 2010.

44. Lacan J. Função e campo da fala e da linguagem (1953). Rio de Janeiro: Jorge Zahar Editores; 1988.

45. Figueiredo MD, Onocko-Campos R. Saúde mental na atenção básica à saúde de Campinas - SP: uma rede ou um emaranhado? Ciênc Saúde Coletiva 2009; 14:129-38

46. Winnicott DW. A criança e seu mundo. 6a Ed. Rio de Janeiro: LTC; 2008.

47. Amarante P. Saúde mental e atenção psicossocial. Rio de Janeiro: Editora Fiocruz; 2007. 


\section{Abstract}

The aim was to analyze the peregrination of families of children treated in a Center for Psychosocial Care for Children and Adolescents in their search for mental health care. The study included participant observations at the clinic and focus groups with the children's families. The qualitative study used institutional analysis as the theoretical and methodological reference, and the material was discussed in light of the approach to psychosocial care. The families' search in the face of the child's psychological distress is a prime indicator for assessing strengths and weaknesses in building the network of care, and for revealing the families' understanding of their children's mental health problems and treatments. The study found contradictory forces at play in daily care, demonstrating both the provider's transformative force and occasionally the user's crystallization and maintenance. In this sense, the hegemonic model - disease-centered, fragmenting patients and their care - has been challenged by the instituting force that proposes to reposition the patient and incorporate psychological distress as part of overall health, linking services and actions in a model of care. Despite the tangled maze that families face in their peregrination for care, strides have been made in psychosocial care, while highlighting challenges. Such progress has been anchored in relational technologies (shelter, bonding, trust, and accountability) with the various actors involved in the care.

Mental Health; Child; Health Services

\section{Resumen}

El objetivo de este estudio fue analizar el itinerario recorrido por las familias de niños atendidos en un Centro de Atención Psicosocial Infantojuvenil, en búsqueda de un tratamiento de salud mental. Se realizaron Observaciones Participantes del servicio estudiado y Grupos Focales con familiares de niños atendidos. La investigación cualitativa utilizó como aporte teórico-metodológico el Análisis Institucional y el material se discutió, teniendo en vista la forma de atención psicosocial. La búsqueda de los familiares, cuando se enfrentan al sufrimiento psíquico de un niño, es un indicador privilegiado para aquilatar potencialidades y fragilidades en la construcción de la red de atención, así como para revelar la compresión de los familiares respecto a los problemas de salud mental y sus tratamientos. Se verificó la presencia de fuerzas contrapuestas en las acciones cotidianas de atención, bien sea la fuerza transformadora del instituyente, bien sea la cristalización de la atención y mantenimiento del instituido. En este sentido, el modelo hegemónicamente instituido -enfocado en la enfermedad, fragmentando al sujeto y la atención a él dirigidaha sido tensionado por una fuerza instituyente, que propone reposicionar el sujeto, así como incorporar el sufrimiento psíquico, como integrante de la salud general, coordinando servicios y acciones en un modelo de red. A pesar del conjunto de situaciones embarazosas a las que se tienen que enfrentar los familiares en su peregrinación por los cuidados, existen avances que van en la dirección de la atención psicosocial y apuntan a desafíos que deben enfrentarse. Tales avances están anclados en las tecnologías de las relaciones -acogida, vínculo, confianza y responsabilización entre los diversos actores involucrados en el cuidado.

Salud Mental; Niño; Servicios de Salud
Recebido em 18/Ago/2016

Versão final reapresentada em 21/Mar/2017

Aprovado em 03/Abr/2017 